\title{
Reporting cervical effacement as a percentage: How accurate is it?
}

\author{
Radha Malapati*, Yen N. Vuong, Tuan M. Nguyen \\ Department of Obstetrics and Gynecology, Division of Maternal-Fetal Medicine, John H. Stroger Hospital, Chicago, USA \\ Email: "radha malapati@yahoo.com
}

Received 7 August 2013; revised 28 August 2013; accepted 3 September 2013

Copyright (C) 2013 Radha Malapati et al. This is an open access article distributed under the Creative Commons Attribution License, which permits unrestricted use, distribution, and reproduction in any medium, provided the original work is properly cited.

\begin{abstract}
Objective: To evaluate the accuracy of cervical effacement reported as a percentage by digital cervical exams using cervical length determined by transvaginal ultrasonography as a standard. Methods: Records of pregnant women who had a digital cervical exam and subsequent transvaginal ultrasound scan for cervical length between January 2005 and December 2008 were reviewed. Digital cervical exams were performed by different examiners. Transvaginal ultrasound was performed by one examiner who did not perform any of the digital exams. Cervical effacements were recorded as a percentage and cervical lengths were measured in centimeters. Results: A total of 173 women met the study criteria. Average cervical length for $0 \%$ effacement was $3.3 \pm 1.1 \mathrm{~cm} \mathrm{(0.8} \mathrm{-}$ $5.0 \mathrm{~cm}) ; 20 \%$ effacement, $1.6 \pm 1.0 \mathrm{~cm}(0.9-3.0 \mathrm{~cm})$; $25 \%$ effacement, $2.2 \pm 0.2 \mathrm{~cm}(2.0-2.3 \mathrm{~cm}) ; 30 \%$ effacement, $2.6 \pm 0.4 \mathrm{~cm}(2.1-3.0 \mathrm{~cm}) ; 40 \%$ effacement, $3.0 \pm 0.4 \mathrm{~cm}$ (2.6 - $3.4 \mathrm{~cm}) ; 50 \%$ effacement, $2.4 \pm 1.1$ cm (0.6 - $4.6 \mathrm{~cm}) ; 60 \%$ effacement, $2.3 \pm 1.4 \mathrm{~cm}(0.7$ $4.3 \mathrm{~cm}) ; 70 \%$ effacement, $2.2 \pm 0.8 \mathrm{~cm}(1.1-3.3 \mathrm{~cm})$; $75 \%$ effacement, $1.7 \pm 1.4 \mathrm{~cm}(0.7-2.7 \mathrm{~cm}) ; 80 \%$ effacement, $2.0 \pm 0.9 \mathrm{~cm}(0.6-4.4 \mathrm{~cm}) ; 90 \%$ effacement, $0.7 \pm 0.4 \mathrm{~cm}(0.4-0.9 \mathrm{~cm}) ; 100 \%$ effacement, $1.2 \pm 1.5$ cm $(0.3-3.0 \mathrm{~cm})$. The coefficient of variation ranges from $10 \%-124 \%$. Conclusion: The traditional method of reporting cervical effacement as a percentage is unacceptably inaccurate compared to the actual cervical length determined by vaginal probe ultrasound.
\end{abstract}

Keywords: Cervical Effacement; Cervical Length; Transvaginal Ultrasound

\section{INTRODUCTION}

Cervical effacement, the shortening of the cervical canal

*Corresponding author. as the functional approaches of internal os and external os, is accomplished by the gradual incorporation of the substance of the cervix into the lower uterine segment. Cervical effacement is commonly expressed as a percentage of the presumed length of the uneffaced cervix. However, there is no consensus regarding the length of the uneffaced cervix before labor begins. The $23^{\text {rd }}$ edition of Williams Obstetrics indicates that the approximate length of the cervix is $2 \mathrm{~cm}$ prior to the onset of labor [1]. Yet transvaginal ultrasound studies of the cervix show that the median cervical length ranges from 3.5 to $4.0 \mathrm{~cm}$ at 24 and 28 weeks and 3.0 to $3.5 \mathrm{~cm}$ after 32 weeks [2]. The aim of our study was to evaluate the accuracy of cervical effacement reported as a percentage by digital cervical exams using cervical length determined by transvaginal ultrasonography as a standard.

\section{METHODS}

This retrospective study was approved by the institutional review board at Stroger Hospital of Cook County, Chicago, Illinois, USA. Data were collected from Stroger Hospital of Cook County Perinatal Network between January 2005 and December 2008. Women who had a digital cervical exam and subsequent transvaginal ultrasound scan for cervical length were included. Digital cervical exams were performed by different examiners within our perinatal network. Cervical effacement was reported as a percentage. A transvaginal ultrasound scan was performed by one of the authors (TN) who did not perform any of the digital exams. All transvaginal ultrasound scans were done at our institution upon patient arrival within 30 minutes of vaginal exams. A Toshiba ECCOCEE Model SSA_340A (Otawara-Shi, TogichiKen, Japan) or Siemens Sonoline Elegra (Issaquah, Washington, USA) ultrasound system with a $7 \mathrm{MHz}$ endovaginal transducer was used to measure cervical length according to a technique described by Iams et al. [3]. The procedure was done with women in the supine position 
with empty bladders. Care was taken not to put pressure on the cervix. The entire cervical canal was visualized in the sagittal plane. Cervical length was measured from the internal os to the external os and recorded in centimeters. Three measurements were routinely obtained at each study. Intraobserver variability was $3.5 \%$. Average cervical length was calculated and used for data analysis. The following data were also collected for each woman: maternal age, gravidity, parity, gestational age, and indications for cervical evaluation. Data were analyzed with descriptive statistics on SPSS version 17.0 for Windows XP (SPSS Inc., Chicago, IL, USA).

\section{RESULTS}

A total of 173 women met the study criteria. Maternal characteristics are summarized in Table 1. Indications for cervical evaluation were threatened preterm labor (55\%) and induction of labor (45\%). Of the 173 digital exams, 50 (29\%), 28 (16\%), and 95 (55\%) were performed by attending physicians, nurse midwives, and resident physicians, respectively. Vaginal exams were performed by $2^{\text {nd }}, 3^{\text {rd }}$ and $4^{\text {th }}$ year residents. Cervical effacements were compared to cervical lengths determined by transvaginal ultrasonography (Figure 1). Cervical effacements and corresponding cervical lengths were grouped according to percentage, and a range of cervical lengths was observed for each effacement group (Table 2). The distributions of cervical lengths are shown in Figure 2 for 0\% effacement and Figure 3 for 50\% effacement.
Table 1. Maternal characteristics of the study group.

\begin{tabular}{cc}
\hline Maternal age (years) & $25.2 \pm 6.4$ \\
\hline Gravidity & $3.0 \pm 2.0$ \\
Parity & $2.0 \pm 1.0$ \\
Gestational age (weeks) & $33.0 \pm 4.7$ \\
\hline
\end{tabular}

Data are shown as mean \pm standard deviation.

Table 2. Vaginal probe ultrasound of cervical length vs percent cervical effacement by pelvic examination.

\begin{tabular}{cccc}
\hline $\begin{array}{c}\text { Cervical } \\
\text { effacement }(\%)\end{array}$ & $\begin{array}{c}\text { Cervical } \\
\text { length }(\mathrm{cm})\end{array}$ & $\begin{array}{c}\text { Range of cervical } \\
\text { length }(\mathrm{cm})\end{array}$ & $\begin{array}{c}\text { Coefficient of } \\
\text { variation }(\%)\end{array}$ \\
\hline $0(\mathrm{n}=82)$ & $3.3 \pm 1.1$ & $0.8-5.0$ & 32 \\
$20(\mathrm{n}=4)$ & $1.6 \pm 1.0$ & $0.9-3.0$ & 60 \\
$25(\mathrm{n}=2)$ & $2.2 \pm 0.2$ & $2.0-2.3$ & 10 \\
$30(\mathrm{n}=5)$ & $2.6 \pm 0.4$ & $2.1-3.0$ & 14 \\
$40(\mathrm{n}=3)$ & $3.0 . \pm 0.4$ & $2.6-3.4$ & 13 \\
$50(\mathrm{n}=33)$ & $2.4 \pm 1.1$ & $0.6-4.6$ & 47 \\
$60(\mathrm{n}=8)$ & $2.3 \pm 1.4$ & $0.7-4.3$ & 60 \\
$70(\mathrm{n}=10)$ & $2.2 \pm 0.8$ & $1.1-3.3$ & 32 \\
$75(\mathrm{n}=2)$ & $1.7 \pm 1.4$ & $0.7-2.7$ & 83 \\
$80(\mathrm{n}=19)$ & $2.0 \pm 0.9$ & $0.6-4.4$ & 45 \\
$90(\mathrm{n}=2)$ & $0.7 \pm 0.4$ & $0.4-0.9$ & 54 \\
$100(\mathrm{n}=3)$ & $1.2 \pm 1.5$ & $0.3-3.0$ & 124 \\
\hline
\end{tabular}

Data are shown as mean \pm standard deviation.

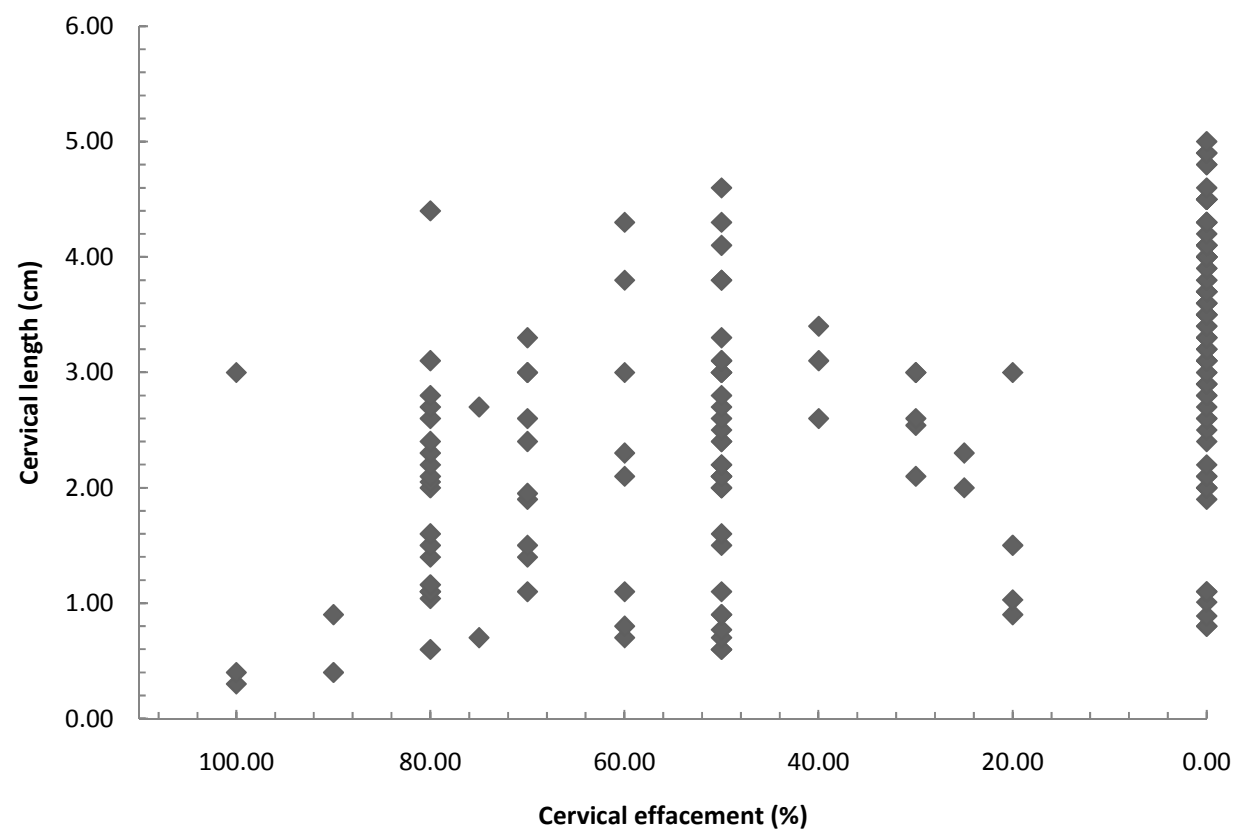

Figure 1. Vaginal probe ultrasound of cervical length vs percent cervical effacement by digital examination. 


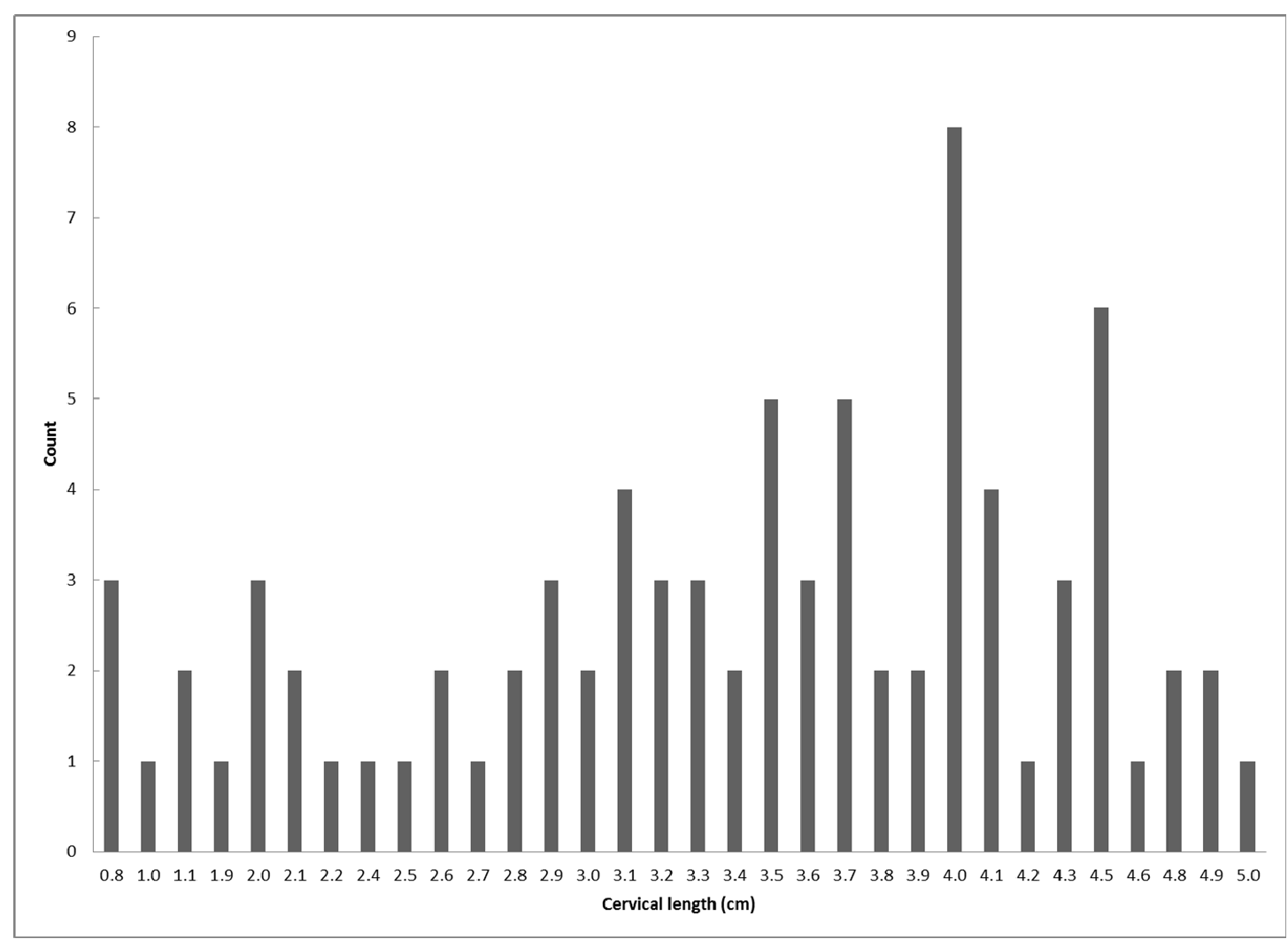

Figure 2. Cervical lengths reported as $0 \%$ effacement $(n=82)$.

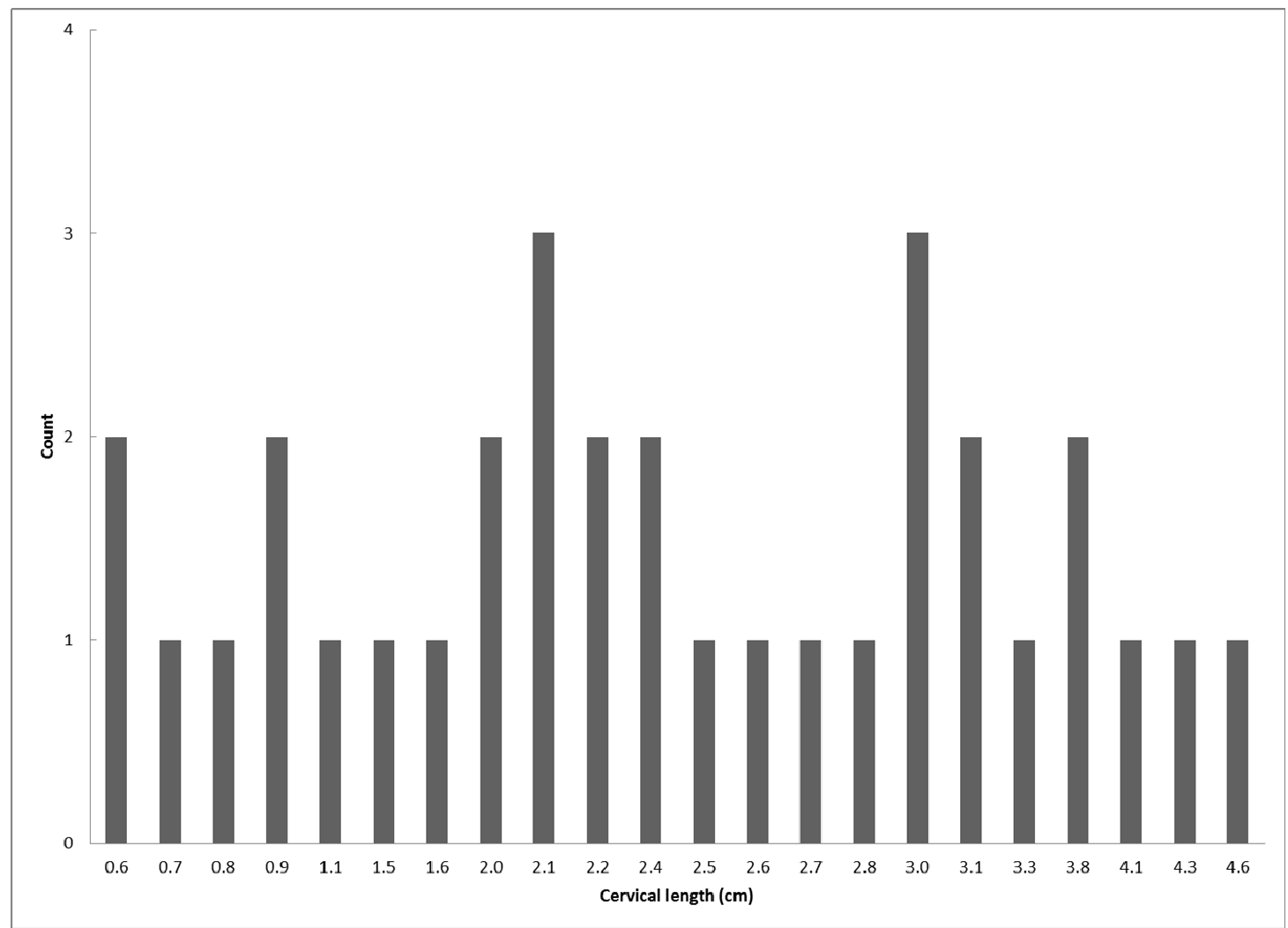

Figure 3. Cervical lengths reported as $50 \%$ effacement $(n=33)$. 


\section{DISCUSSION}

Cervical effacement is one of the parameters used to predict the inducibility of the cervix [4] and evaluate whether or not preterm labor has occurred. Cervical effacement can be reported as a percentage or as a length in centimeters. The percentage system assigns 0 to the uneffaced cervix and 100 to the obliterated cervix. Cervical effacement documented in centimeters reflects the length of the remaining cervical canal. While both methods are acceptable, describing cervical effacement in terms of percentage lacks standardization. The estimated degree of effacement is based on the assumed length of the uneffaced cervix, which may vary from examiner to examiner. A survey by Holcomb and Smeltzer [5] demonstrated that physicians differ in their impressions of cervical length in the third trimester. Our study confirms the results of the survey.

The evaluation of cervical effacement as a percentage appears subjective. Many cervical lengths measured by transvaginal ultrasound were associated with each degree of cervical effacement (Figure 1). It is apparent that those who performed the digital cervical exam had various perceptions of the length of the uneffaced cervix. Transvaginal ultrasonography showing cervical lengths between 0.8 and $5.0 \mathrm{~cm}$ was reported as $0 \%$ effacement (Figure 2). When a cervix shortens to half its original length, it is said to be $50 \%$ effaced. If all clinicians accepted a common length for the uneffaced cervix, the cervical length associated with $50 \%$ effacement should not be significantly different. Our data show that many cervical lengths were attributed to $50 \%$ effacement (Figure 3). Cervical lengths from 0.6 to $4.1 \mathrm{~cm}(\mathrm{n}=33)$ were reported as $50 \%$ effacement. The coefficient of variation was $33 \%$. Similar patterns are seen with other effacements.

Reporting cervical effacement as a percentage is oversimplified and does not account for the physiological changes that accompany advancing gestation. The progressive shortening of the cervix in the third trimester requires the establishment of an arbitrary time 0 at which the cervix is uneffaced. The time chosen will define the length of the original cervix pre-labor and affect subsequent assessments. Differences in cervical length depending on gestational age may also alter preconceived notions examiners have concerning the length of the uneffaced cervix.

Given the inaccuracy of reporting cervical effacement as a percentage, describing actual cervical length in centimeters may be better. Using centimeters to estimate cervical length entails "calibrating” one's fingers while maintaining the same cervical examination technique. Where cervical assessment boards with rings of different dilatations are available for cervical dilatation practice, straight rulers can be used for cervical effacement calibration. The advantage of reporting cervical effacement in centimeters is that the estimate reflects the length of the remaining cervical canal. No assumptions are made regarding the length of the uneffaced cervix. As a result, reports of cervical effacement would be more consistent.

One of the limitations of our study was the possibility that some examiners might have performed more than one cervical exam, which may have skewed the results. However, since data were collected over a 4-year period, it would be unlikely that the results would have been significantly affected. Another limitation is small sample sizes for some percentages of cervical effacement. In spite of this limitation significant variation in cervical length was still noted for these groups. Strengths of this study were: 1) cervical exams were done by various obstetric clinicians; 2) all transvaginal ultrasound scans were done by one of the authors who did not perform any of the digital cervical exams.

Cervical effacement is the only component of the cervical exam that does not have a point of reference. As a result, the traditional method of reporting cervical effacement as a percentage is unacceptably inaccurate compared to the actual cervical length determined by vaginal probe ultrasound.

\section{REFERENCES}

[1] Cunningham, F.G., Leveno, K.J., Bloom, S.L., Hauth, J.C., Rouse, D.J. and Spong, C.Y. (2010) Parturition. In: Cunningham, F.G., Leveno, K.J., Bloom, S.L., Hauth, J.C., Rouse, D.J. and Spong, C.Y., Eds., Williams Obstetrics, 23rd Edition, McGraw-Hill, New York, 143.

[2] Creasy, R.K., Resnik, R. and Iams, J.D. (2004) Abnormal cervical competence. In: Creasy, R.K., Resnik, R. and Iams, J.D., Eds., Maternal-Fetal Medicine Principles and Practice, 5th Edition, Saunders, Philadelphia, 604.

[3] Iams, J.D., Johnson, F.F., Sonek, J., Sachs, L., Gebauer, C. and Samuels, P. (1995) Cervical competence as a continuum: A study of ultrasonographic cervical length and obstetric performance. American Journal of Obstetrics \& Gynecology, 172, 1097-1106. doi:10.1016/0002-9378(95)91469-2

[4] Newman, R.B., Goldenberg, R.L., Iams, J.D., Meis, P.J., Mercer, B.M., Moawad, A.H., Thom, E., Miodovnik, M., Caritis, S.N., Dombrowski, M. and Thurnau, G.R. (2008) Preterm prediction study: Comparison of the cervical score and Bishop score for prediction of spontaneous preterm delivery, Obstetrics \& Gynecology, 112, 508-515. doi:10.1097/AOG.0b013e3181842087

[5] Holcomb, W.L. and Smeltzer, J.S. (1991) Cervical effacement: Variation in belief among clinicians. Obstetrics \& Gynecology, 78, 43-45. 